\title{
CONTRIBUIÇÃO AO ESTUDO ANATOOMICO DA ESPÉCIE CATHARANTHUS ROSEUS (L.) G. DON VAR. ROSEUS (APOCYNACEAE)
}

\author{
JANETTE MACIEL PACHECO \\ Professor Adjunto e Livre \\ Docente da UFF.
}

\section{INTRODUÇÃo}

A espécie Catharanthus roseus (L.) G. Don, var. roseus é mais conhecida na linguagem popular como "vinca" e "boa-noite". Planta ornamental, originária de Madagascar, aclimatou-se em todos os países de clima tropical inclusive o Brasil, onde é encontrada em quase todos os jardins.

Sua utilização na medicina popular data de algumas décadas, destacando-se as partes aéreas, principalmente as folhas como antifebrifugas, adstringentes, em certas afecçōes cutâneas e também como antidiabéticas. As raizes são consideradas purgativas, vermifugas e febrifugas (R. PARIS - 1971).

As experiências cientificas mostraram que estas plantas, notadamente raízes e folhas, apresentam riqueza em alcalóides do grupo Indólico. Constatamos também que (SVOBODA e FARNSWORTH et al - 1964), indicam que as folhas encerram perto de 60 alcalóides, dos quais 2 mostraram grande utilidade na terapêutica: Vimblastina e Vincristina. Segundo TREASE e EVANS - 1978, atualmente os alcalóides totalizam cerca de 70 , dos quais aqueles acima citados estão em uso, possuindo propriedades anticancerígenas (TAYLOR e FARNSWORTH - 1975).

Verificou-se que o alcalóide denominado primeiramente de Ajmalicina e atualmente Raubasina, detém apreciável atividade antiarrítmica, podendo substituir a Piridina nos casos de arritmia miocárdica (RIZZINI e MORS - 1976).

\section{MATERIAL E MÉTODOS}

O material que serviu para estas experiências foi coletado nos jardins da Faculdade de Farmácia da UFF e Jardim Botânico do Rio de Janeiro.

Os cortes, para exame microscópico, foram feitos com auxilio da navalha histológica e os fragmentos da planta fresca colocados entre medula de embaúba e em seguida presos no micrótomo tipo Ranvier. 
Preparamos lâminas semi-permanentes $\mathrm{e}$ inicialmente diafanizamos os cortes com a solução de hipoclorito de sódio a $50 \%$; em seguida foram os mesmos lavados com água acética, água e corados com solução de verde-iodo a $1 \%$ em álcool etílico a $50 \%$ : passamos logo depois no álcool a 909, água, vermelho do congo e finalmente montamos em gelatina-glicerinada.

A dissociação epidérmica para identificação dos elementos anatômicos foi feita com a maceração de Schulze (cristais de clorato de potássio e ácido nítrico a $10 \%$ em partes iguais). Após a dissociação, foram as mesmas passadas em água destilada, coradas pela safranina e montadas em gelatina-glicerinada.

Em nossas observaçöes, utilizamos o microscópio Bausch-Lomb (ocular 10Xe objetivas: $6 \mathrm{X}, 10 \mathrm{X}$ e $44 \mathrm{X}$ ).

As medidas dos elementos microscópicos foram realizadas com auxilio da ocular micrométrica de "Leitz", após prévio cálculo do coeficiente micrométrico, utilizando para tal, o micrômetro objetivo "Leitz" de $0,01 \mathrm{~mm}$.

As fotomicrografias foram obtidas através do fotomicroscópio Jena, pertencente a Disciplina de Farmacognosia da Faculdade de Farmácia da UFF.

\section{ESTUDO ANATÔMICO}

\section{Folha}

Em material dissociado, observamos:

Epiderme adaxial - quando examinada de face - Fig. 1, mostra células de paredes levemente onduladas, freqũentemente de 5-6 lados, de formas e tamanhos variáveis. Constatamos a presença de apreciável número de estomas do tipo anomocítico e em menor freqüência os do tipo paracítico, geralmente solitários, acompanhados por 4.5 células anexas. Encontramos, aqui, pelos tectores uni e pluricelulares, unisseriados, cônicos, com membrana estriada, agudos no ápice e alguns levemente recurvados.

Epiderme abaxial - examinada de face - Fig. 2 e 3, está constituída por células de paredes onduladas, mostrando geralmente 5-6 lados, de formas e tamanhos variáveis, menores ,ue as componentes da epiderme adaxial. Encontramos numerosos estomas do tipo anomocítico e com freqüência bem reduzida os do tipo paracítico. quase sempre solitários, acompanhados por $\mathbf{4 - 5}$ células anexas.

Observamos maior abundância de pêlos tectores idênticos aos já descritos acima.

\section{Limbo}

Em secção transversal do limbo - Figs. 4 e 5, observamos:

Epiderme adaxial - mostrando uma única fileira de células de forma aproximadamente poligonal, medindo em média 25 - 40 micra na direção periclínea por 15 - 
20 micra na anticlínea, revestida por uma cutícula com cerca de 10 micra de espessura.

Epiderme abaxial - uniestratificada, apresentando as células um tanto menores que as componentes da epiderme superior, medindo na direção periclínea $20-32$ micra e na anticlínea $15-20$ micra. A cutícula mostra-se mais delgada que a anterior, atingindo cerca de 8 micra.

Constatamos que, tanto a epiderme superior como a inferior, apresentam pêlos tectores idênticos aos já descritos, sendo entretanto mais abundantes na inferior.

Mesofilo - heterogêneo, assimétrico, mostrando uma única fileira de células do tecido paliçádico, bastante desenvolvidas, constituindo cerca de $50 \%$ da espessura do mesofilo, medindo de 65 - 80 micra de altura por 25 - 30 micra de largura e por 5 - 6 fileiras de células do tecido lacunoso.

Observamos aqui, pêlos tectores idênticos aos já descritos - quando da dissociação epidérmica.

\section{Nervura mediana}

Em secção transversal da nervura mediana, Figs. 6 e 7, observamos:

Contorno: bi-convexo, sendo que esta convexidade é um pouco mais acentuada na face inferior.

Epiderme adaxial - mostra uma única fileira de células, medindo internamente de 20 - 30 micra na direção periclínea por 15 - 18 micra na anticlínea. Suas células estão revestidas por uma cutícula ondulada atingindo até 10 micra de espessura.

Epiderme abaxial - do mesmo modo que a superior, é uniestratificada, medindo internamente de $15-18$ micra na direção periclínea por $10-15$ micra na anticlínea, podendo a cutícula medir até 8 micra de espessura.

Tanto a epiderme adaxial como a abaxial, apresentam pêlos tectores idênticos aos já descritos, com predominância na abaxial.

Colênquima - do tipo anguloso, apresentando maior desenvolvimento na região que está voltada para a face adaxial e neste caso, encontramos $4-5$ fileiras de células.

Parênquima - bastante desenvolvido, principalmente na região abaxial, com as células mostrando uma forma aproximadamente isodiamétricas, podendo atingir até 45 micra de diâmetro. 
O feixe vascular apresenta-se em forma de um arco aberto, onde encontramos um líber externo e interno, com todos os seus elementos e observamos que o externo é mais desenvolvido.

O câmbio mostra-se visível em alguns trechos, apresentando $2-3$ fileiras de células de paredes delgadas.

O lenho está constituído por numerosas séries radiais de vasos, separados por meio de estreitos raios medulares, formados quase sempre por $1-2$ séries de elementos. Cada série radial de vasos, está constituída por $2-5$ elementos de metaxilema e 1 - 2 de protoxilema. Constatamos, aqui, ausência de elementos fibrosos

$\mathrm{Na}$ região correspondente ao feixe vascular, observamos ocorrência de alguns laticíferos.

\section{Pecíolo}

Em secção transversal do pecíolo (Figs. 8 e 9), constatamos:

Contorno: plano ou levemente convexo na face adaxial e fortemente convexo na abaxial, com duas saliências aliformes voltadas para a face adaxial.

Epiderme adaxial - constituída por uma única fileira de células quase sempre poligonais, medindo 18 - 25 micra na direção periclínea por 15 - 18 micra na anticlínea. A cutícula não ultrapassa a 8 micra de espessura.

Epiderme abaxial - uniestratificada, mostrando células menores que as componentes da epiderme adaxial, mostrando 12 - 20 micra na direção periclínea por 10 15 micra na anticlínea. É recoberta com uma cutícula ondulada medindo aproximadamente 6 micra de espessura.

Em ambas epidermes, observamos a ocorrência de estomas e pêlos tectores já descritos anteriormente.

Colênquima - do tipo anguloso, mostrando-se mais desenvolvido na região que está voltada para a face adaxial e aqui encontramos de $4-5$ fileiras de células. É também encontrado na extremidade de cada saliência aliforme.

Quase todo o órgão é preenchido de parênquima e na região voltada para a face abaxial, observamos células maiores, de forma aproximadamente isodiamétricas, atingindo até $\mathbf{4 5}$ micra de diâmetro.

O feixe vascular mostra-se como na descrição da nervura mediana, em arco aberto, onde destaca-se um líber externo e interno com todos os seus elementos, apresentando o externo maior desenvolvimento. células.

O câmbio visível em certos trechos, está constituído por 2 - 3 fileiras de 
O lenho mostra numerosas séries radiais de vasos, separados por estreitos raios medulares, apresentando quase sempre $1-2$ séries de elementos. Cada série radial de vasos está constituída por $2-5$ elementos de metaxilema e $1-2$ de protoxilema. Observamos nesta região ausência de elementos fibrosos.

$\mathrm{Na}$ região do feixe vascular presenciamos ocorrência de laticíferos.

\section{Caule Jovem}

Em seç̧ão transversal do caule jovem (Figs. 10, 11 e 12), observamos:

Contorno - irregular, mostrando 4 saliências aliformes.

Epiderme - constituída por uma única fileira de células de forma aproximadamente retangular, medindo na direção periclínea 20 - 30 micra e na anticlínea 15 20 micra; é revestida por uma cutícula que não ultrapassa 10 micra de espessura. Encontramos, aqui, pêlos tectores idênticos aos já descritos e numerosos estomas.

Colênquima - angular, mostrando maior espessura nas saliências aliformes, com 3 - 5 fileiras de células de formas e tamanhos variáveis.

Parênquima cortical - observamos uma faixa de largura relativamente desenvolvida, formada por 8 - 12 fileiras de células de forma aproximadamente isodiamétricas, mostrando pequenos meatos triangulares. Constatamos ocorrência de amido e de laticiferos. tosos.

Periciclo - fibroso descontínuo formado por grupo de elementos esclerenquima-

Liber externo e interno - com todos os seus elementos característicos (vasos crivados, células companheiras e parênquima). Constatamos que o externo é mais desenvolvido, mostrando células de diâmetro apreciável.

Câmbio - bem visível, mostrando 3 - 4 fileiras de células de paredes delgadas.

Lenho - os vasos apresentam-se dispostos em fileiras radiais, quase sempre simples, constituídas geralmente de $4-5$ elementos de metaxilema e $1-2$ de protoxilema.

Tanto na regiäo liberiana como lenhosa, observamos a presença de laticiferos.

Medula - bastante desenvolvida, constituída por células comuns de parênquima, podendo as maiores atingir até 75 micra de diâmetro e encerrando grande quantidade de amido e também laticíferos. 


\section{Caule: Estrutura secundária}

Em secção transversal do caule adulto (Figs. 13 e 14), constatamos:

Contôrno - aproximadamente circular.

Com o início da estrutura secundária, as células localizadas logo abaixo da epiderme, adquirem atividade meristemática, formando assim felógeno que desenvolve súber. 0 exame de caules em várias fases de desenvolvimento mostrou que as primeiras manisfestações de atividade felogênica são observadas após o lenho formar um anel completo. Constatamos que o feloderma mostra um desenvolvimento normal, apresentando logo abaixo do felógeno, $2-3$ fileiras de células.

Córtex com células heterodimensionais, paredes espessadas, mostrando grande quantidade de amido.

Periciclo fibroso descontínuo, formado por grupos maiores e menores de células com membrana espessada e tortuosa.

Liber externo e interno - Constituído por todos os elementos típicos, sendo o externo bem mais desenvolvido.

Câmbio - bem nítido, mostrando várias fileiras de células de paredes delgadas.

Lenho - Com desenvolvimento acentuado, com os elementos vasculares isolados ou agrupados, onde destaca-se os de metaxilema em grande número e os de protoxilema bem reduzidos, situados na região próxima ao liber externo e interno. Constatamos a presença de grande número de fibras e os raios medulares estão representados por 1 , raramente 2 séries de elementos. Os elementos vasculares apresentam pontuações areoladas típicas.

$\mathrm{Na}$ região vascular, observamos ocorrência de laticíferos.

Medula - pouco desenvolvida em comparação com a do caule jovem, mostrando células parenquimáticas de paredes um pouco espessas, com meatos pequenos, podendo atingir até 60 micra de diâmetro e encerrando grande quantidade de amido.

\section{Raiz - Estrutura secundária}

Em seç̧ão transversal da raiz (Figs 15 e 16), observamos:

Forma - aproximadamente circular.

Súber - pouco desenvolvido, mostrando células de paredes delgadas, dispostas irregularmente. 
Constatamos um felógeno discreto, representado por 1 - 2 fileiras de células alongadas na direção periclínea.

O feloderma está constituído por 1 - 2 fileiras de células aproximadamente retangular.

Córtex - de desenvolvimento regular, mostrando células com paredes espessadas, irregulares em forma e tamanho. Nesta região destaca-se grande quantidade de amido.

Encontramos apenas o líber externo, bem nítido, mostrando todos os seus elementos (vasos crivados, células companheiras e parênquima).

Câmbio bem nítido, apresentando $3-4$ fileiras de células de paredes delgadas.

A zona lenhosa é bem desenvolvida, mostrando numerosos elementos vasculares isolados ou agrupados, podendo os maiores atingir até 60 micra de diâmetro, destacando-se os de metaxilema em número bem superior em comparação com os de protoxilema.

Nesta região encotramos raios medulares representados por uma raramente duas séries de elementos e grande número de fibras. Os elementos vasculares mostram pontuações areoladas típicas.

Observação: constatamos ocorrência de laticíferos na zona liberiana e lenhosa.

\section{AGRADECIMENTOS}

A autora agradece a valiosa colaboração da Pesquisadora, Dra. Ida de Vattimo Gil, da Seçäo de Geobotânica, do Jardim Botánico do Rio de Janeiro, onde foi realizado este trabalho.
a valiosa

\section{BIBLIOGRAFIA}

1 - BOKE, N. H Development of the adult Shoot apex and floral initiation in Vinca rosea $L$ Amer $\perp$ Bot 1974, 34: $433-439$.

$2-1$. Development of the perianth in Vinca rosea $L$ Ibidem 1948, 35:413-23.

3 - CLAUS, E. P. \& TYLER, V. R. Farmacognosia. El Ateneo-Editorial, Buenos Aires, 1968, 5. ed. 533 p; p. $285-87$.

4 - DOP. P. \& GAUTIE, A. Manuel de technique Botanique, histologie e microbie vegetales. 2.

5 - DWYER, J. D. The taxonomy of the genera Vinca, Lochnera and Catharanthus. Lloydia, $196427(4): 282-85$

6 - EAMES, A $\downarrow \&$ MAC DANIELS, L H An introduction to plant anatomy. 1 ed. New

7 - ELLIOT, G. F. S. Notes on the fertilization of South African and Madagascar flowering

8 - ESAU, K Anatomy vegetal, trad de José Pons Roselt 2 ed. Barcelona Ed. Omega 1959. $729 \mathrm{p}$.

9 - FARNSWORTH, N. R. The Pharmacognosy of Periwinkles: Vinca and Catharanthus. Lloydia, 1961, 24, p. $105-38$.

$10-\ldots$ Studies on Catharanthus alkaloids. Lloydita, 1964, $27(4): 302-15$.

11 - FONT QUER, P. Dicionário de Botanica. Barcelona Ed. Labor, 1965 1244p

12 - GUERIN, H. P. \& DELAVEAU, P. Sur quelques caracteres histologiques des genres Vinea et Catharanthus. Pl. Med. Phytotherapie, 1968 2 p 281 - 91.

13 - HABERLANDT, G. Physiological plant anatomy. London Macmillan, $1928777 \mathrm{p}$ 
14 - LANGERON, M Pribis de microscopia Paris, Masson Ed 1913. 751p

15 - LAWRENCE, G. H M Vinea and Catharanthus, 1959, Baileya 7 (4): 113 - 19.

16 - MARKGRAF, F. Apocinlceas in FL. llustr. Catarinense, 1968 I tajai, 112 $p$

17 - METCALFE, C. R. \& CHALK, L. Anatomy of the Dicotyledons. Oxford, Clarendon Press. 1950 , V. P.

18 - MOERTEL, C. G. \& REITEMEIER, R. S. Chemotherapy of gastrointestinal cancer. 1967. Surgical clinics of North America, $47(4): 929-51$.

19 - PARIS, R. \& MOYSE, H. Matière medicale. Paris, Masson \& C. E diteurs, 1971, vol. 3 p. 88 .93.

20 - RIZZINI, C. T. Sobre Catharanthus roseus (L.) G. Don (Apocynaceae) e suas variedades. Arquivos do Jardim Botànico do Rio de Janeiro, 1978, Vol. 22p 5- 28

21 - RIZZINI, C. T. \& MORS, W. B. Botànica Econòmica Brasileira 1976. Edit. Pedag. e Univ. Sp. 207p.

22 - STEARN, W. T. Catharanthus roseus, the correct name for the Madagascar perinwickle, 1966. Lloydia, 29: $196-200$.

23 - . A synopsis of the genus Catharanthus (Apocynaceae). 1975. In: W. I. Taylor \& N. R. Farnsworth the Catharanthus Alkaloids. M Dekker, Inc, N. York, p 9-44.

24 - STEBBINS, G. L. Variation and Evolution in plants. 1950. Columbia University Press, New York, 634p.

25 - SVOBODA, G. H. The current status of Catharanthus roseus research. 1964. Lloydia, 27 (4): $275 \cdot 79$.

26 - TREASE, G. E. \& EVANS, W. C. Pharmacognosy. Bailliére Tindall-London, 1978, 11 ed. 784p. p. $626 \cdot 27$.

27 - TAYLOR \& FARNSWORTH. The Catharanthus Alkaloids. Dekker, New York, 1975. 


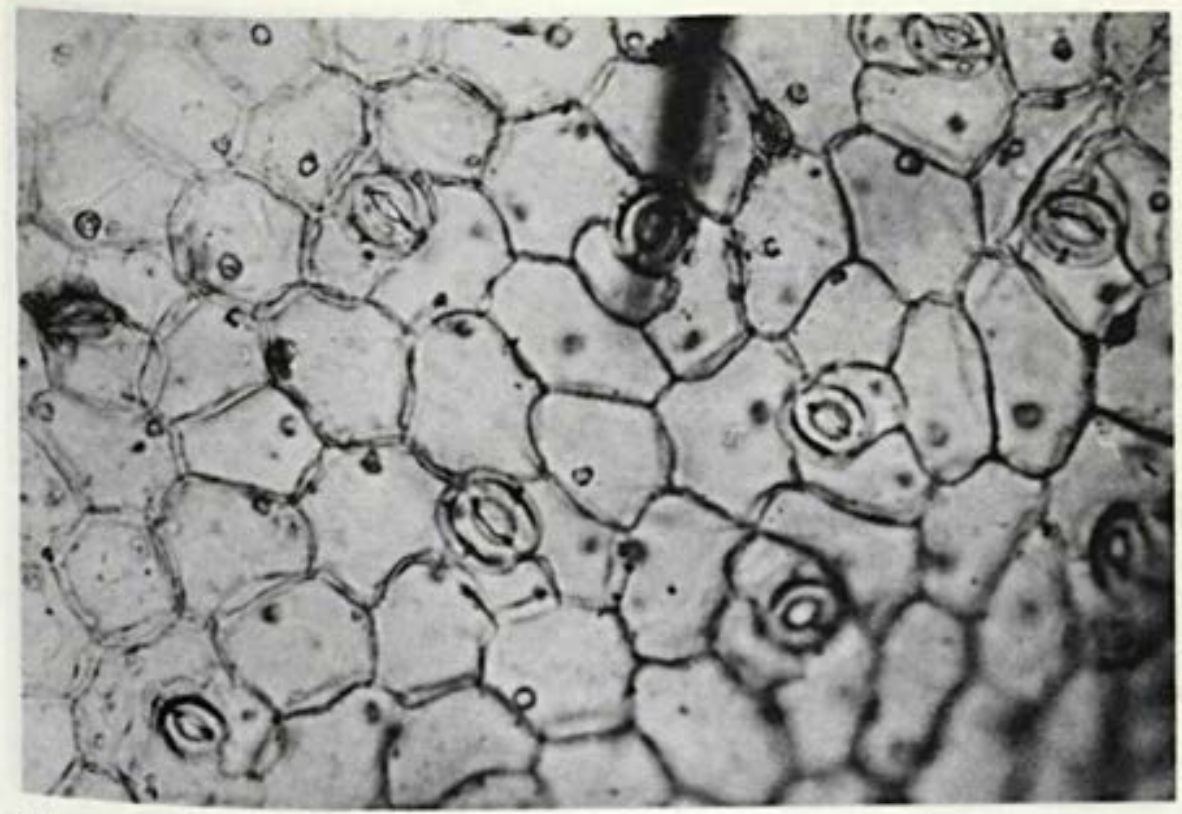

Fig. 1 - Epiderme superior (160 X)

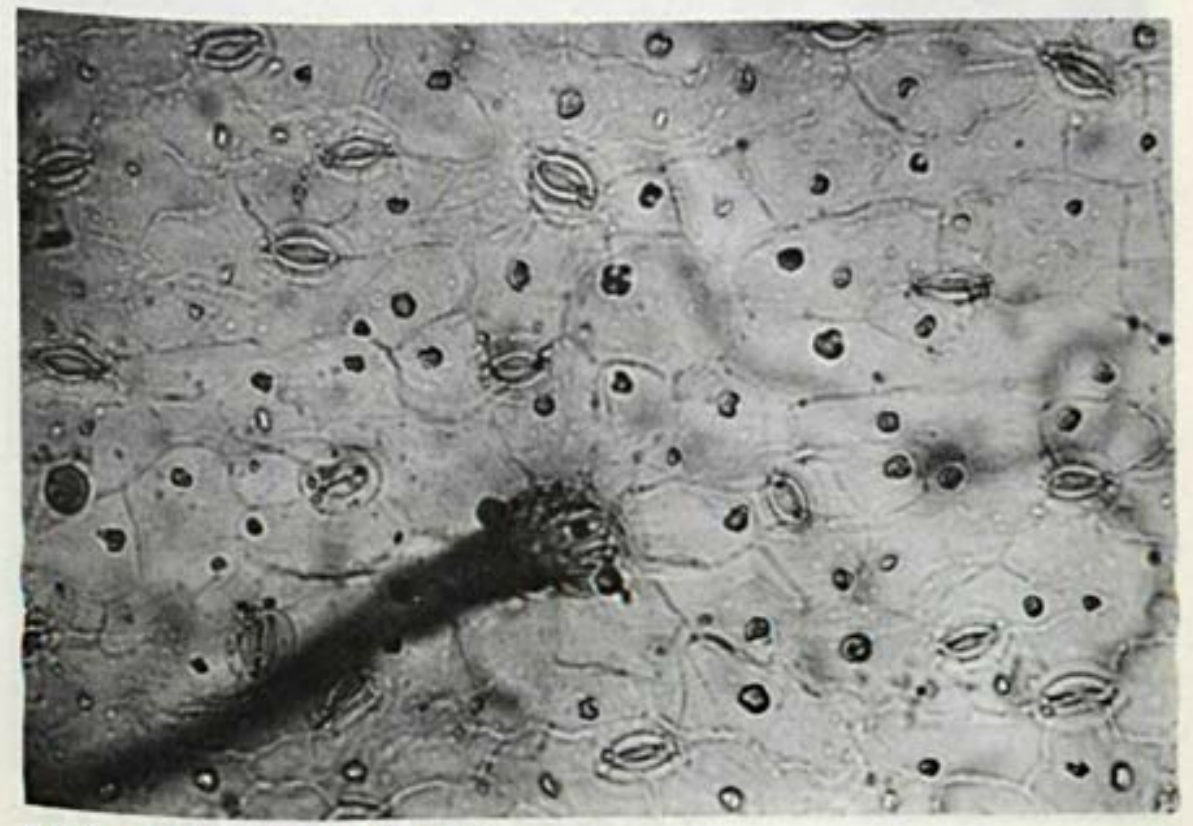

Fig. 2 - Epiderme inferior (160 X) 


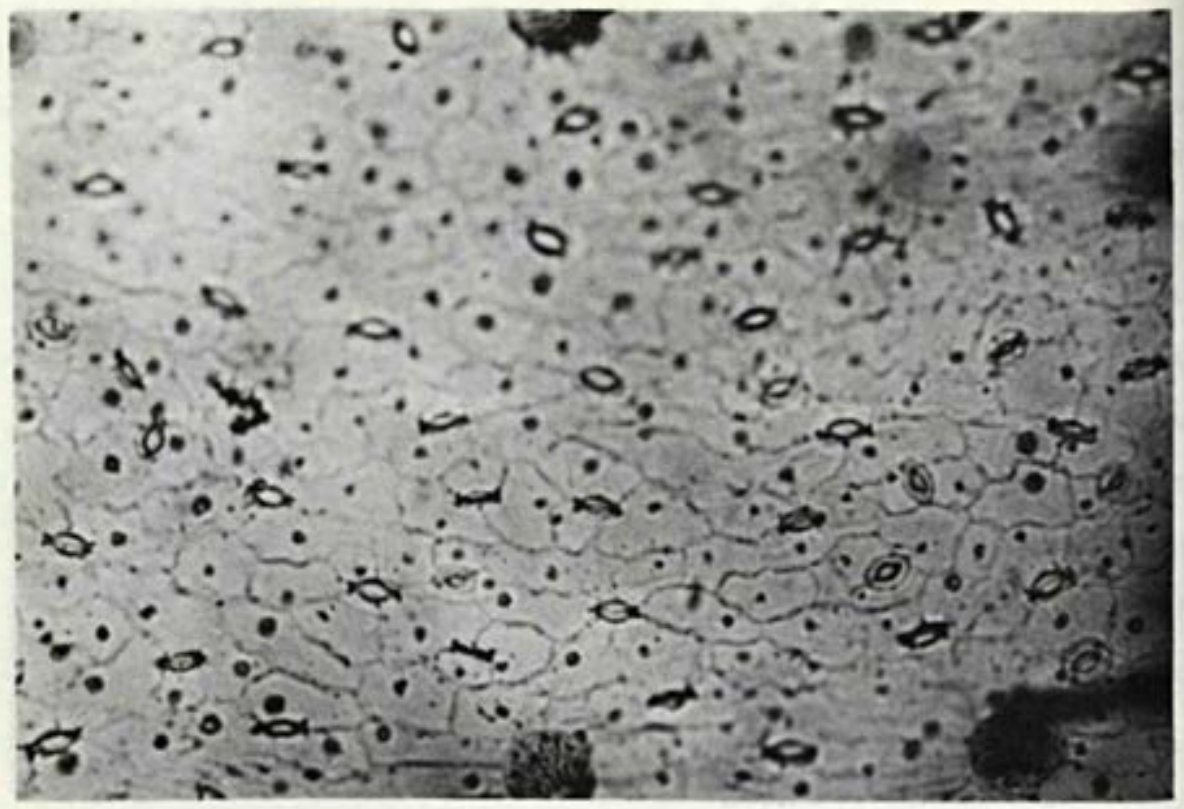

Fig. 3 - Epiderme inferior (100 X)

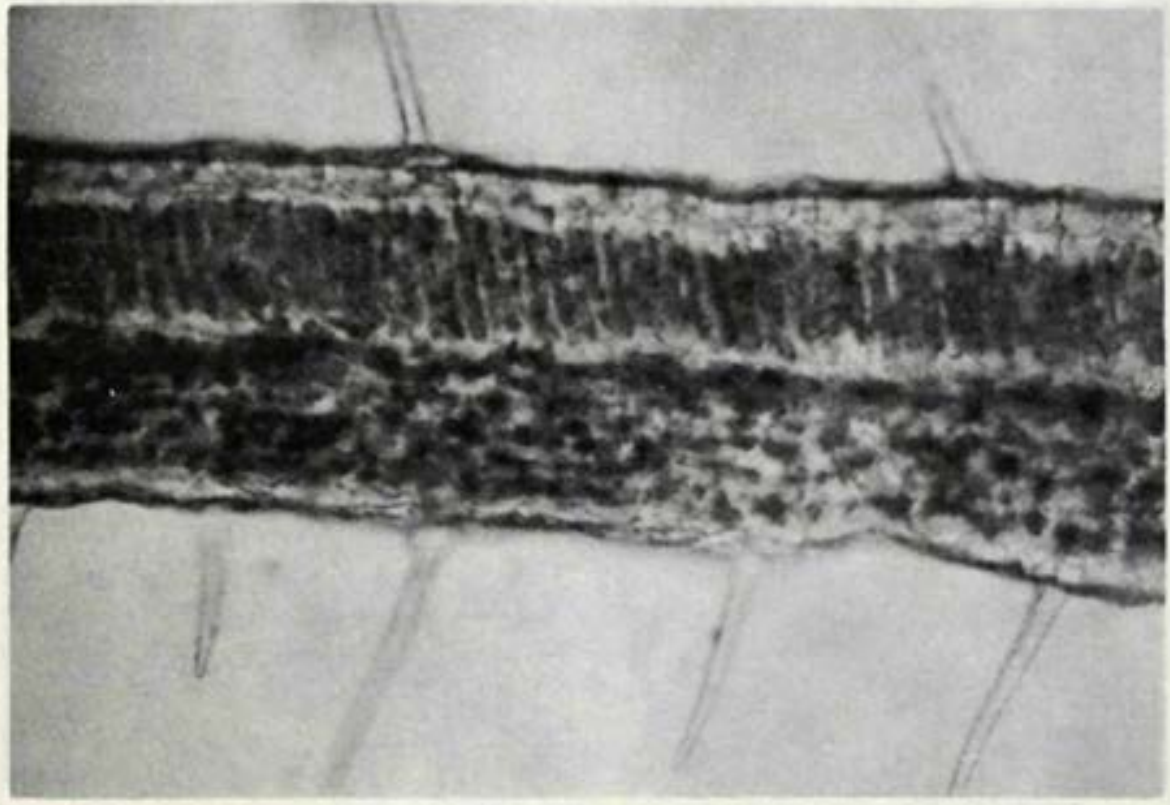

Fig 4 - Corte transversal do limbo $(100 \mathrm{X})$ 


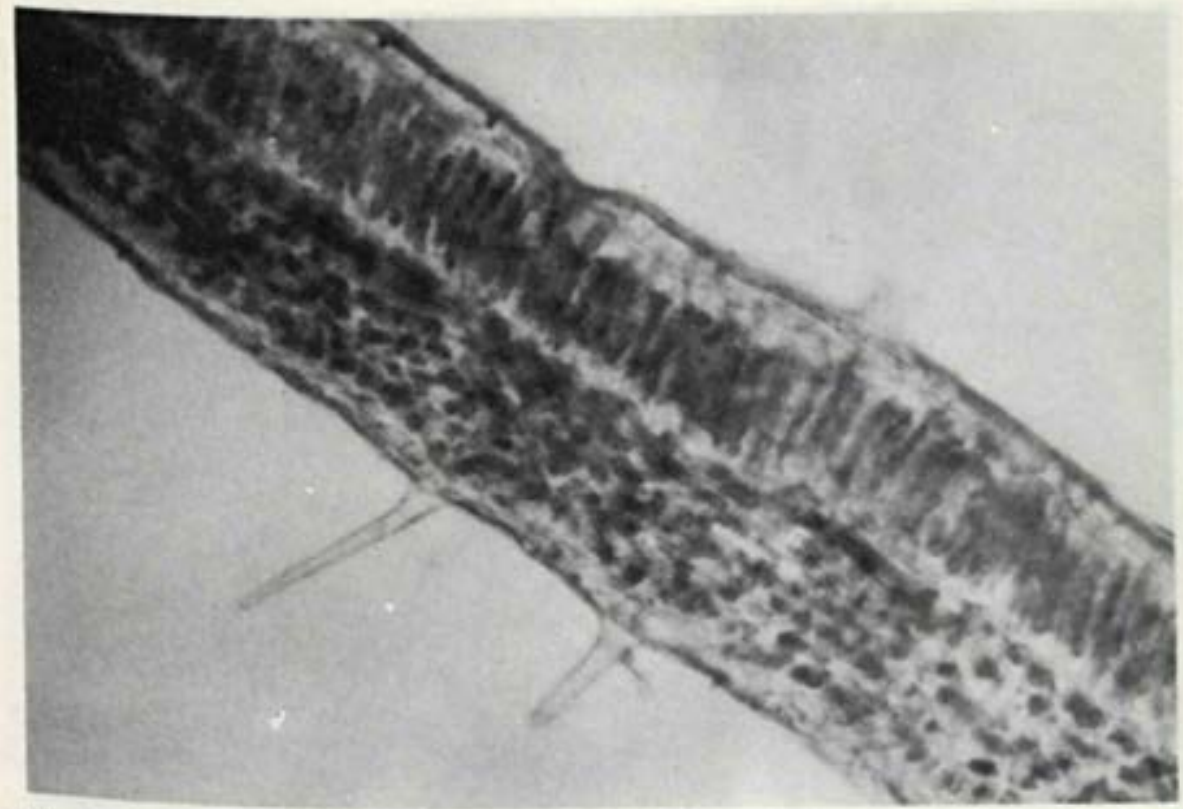

Fig. 5 - Corte transversal do limbo $(100 \times)$

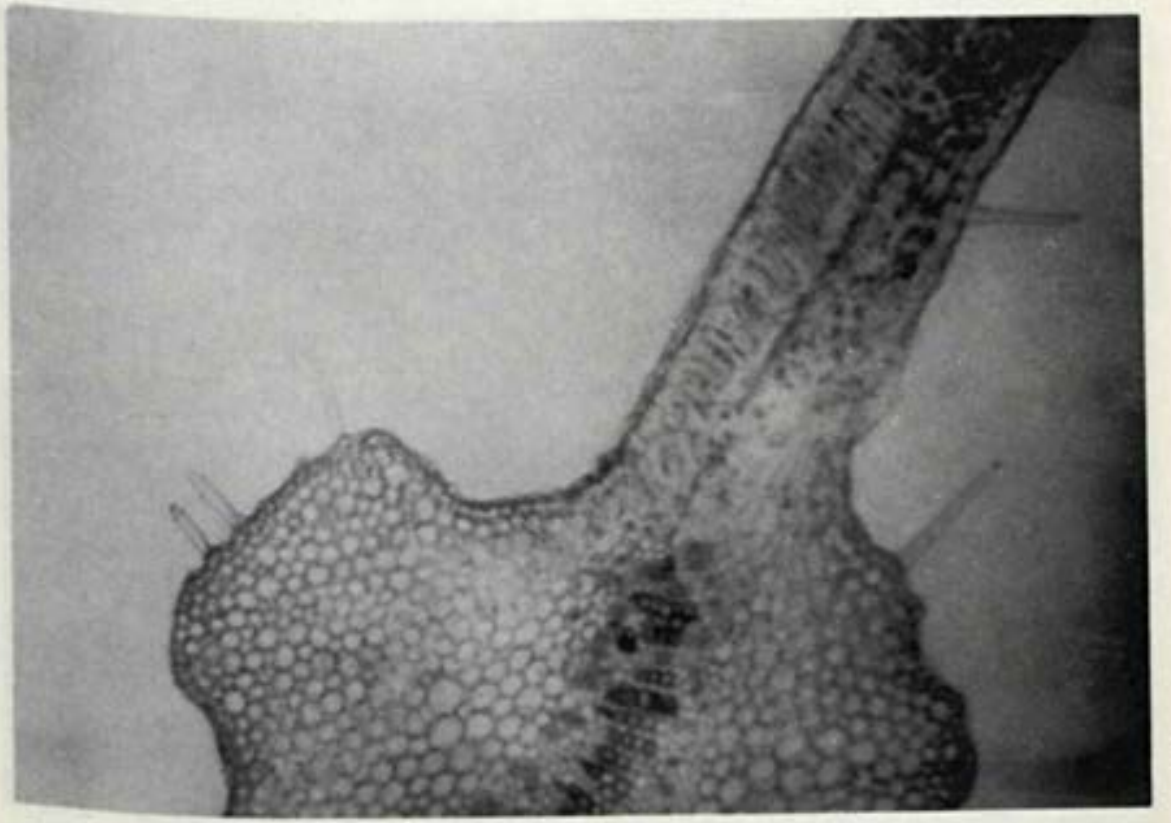

Fig. 6 - Corte transversal da nervura mediada $(25 x)$ 


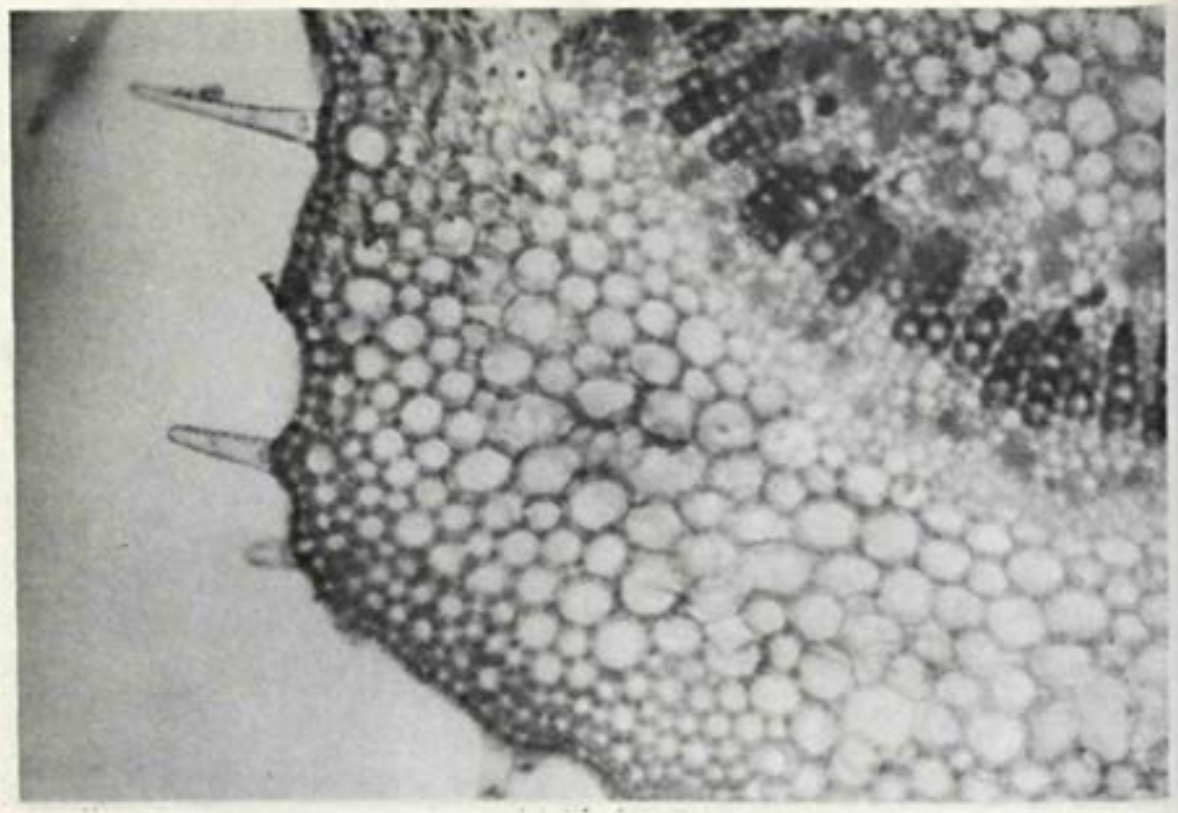

Fig. 7 - Corte transversal da nervura mediana (100 X)

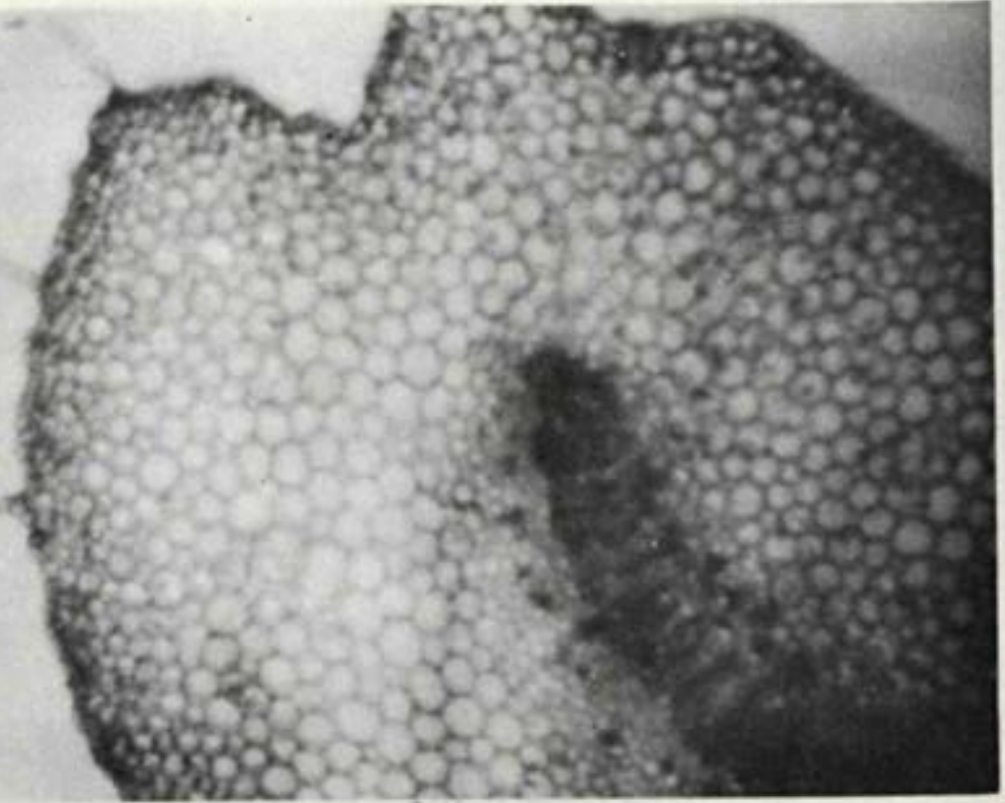

Fig. 8 - Corte transversal do pecfolo $(25 \mathrm{X})$ 


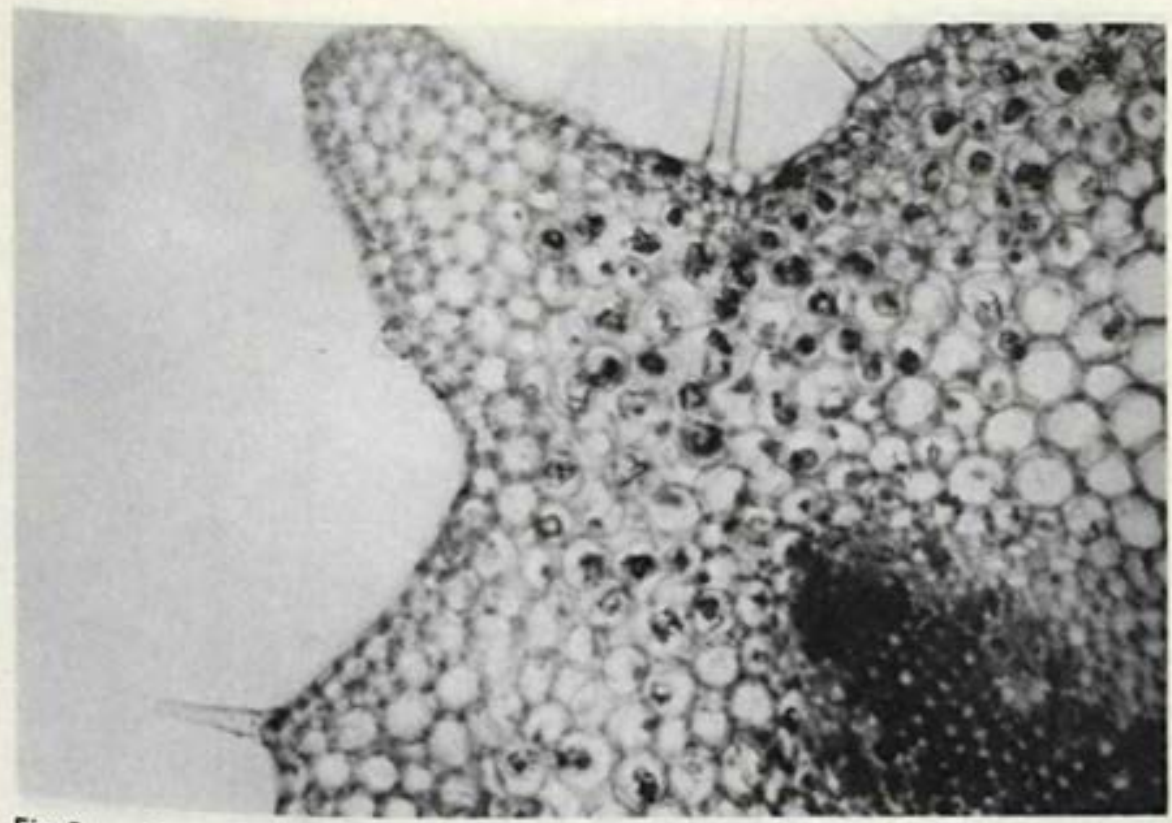

Fig. 9 - Corte transversal do pecíolo $(63 \mathrm{x})$

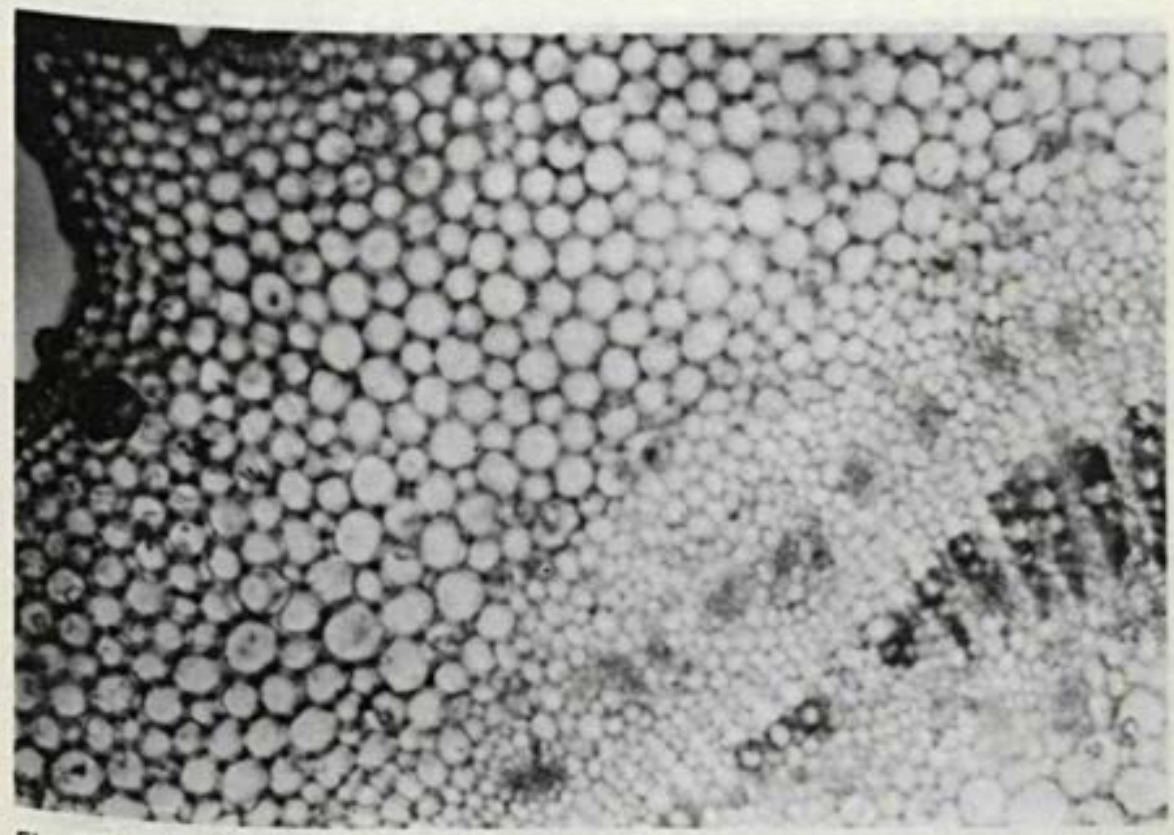

Fig. 10 - Corte transversal do caule jovem (63 X) 


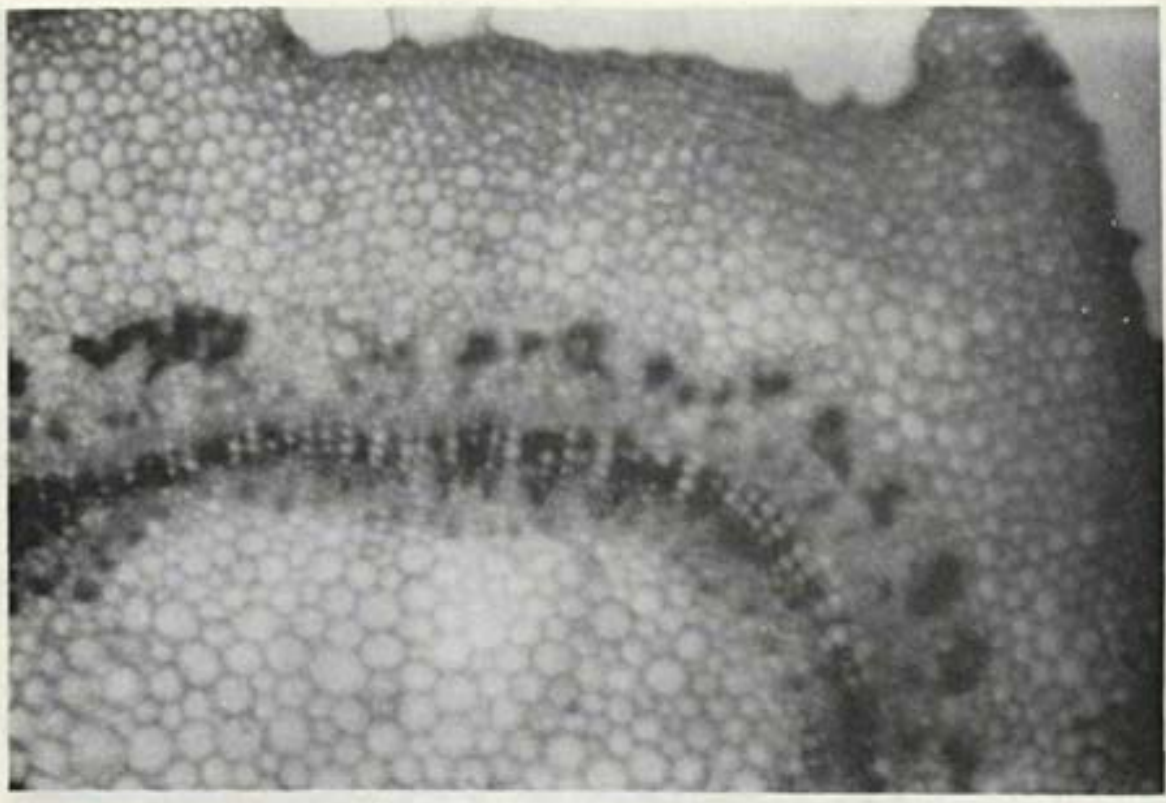

Fig. 11 - Corte transversal do caule jovem $(25 \mathrm{X})$

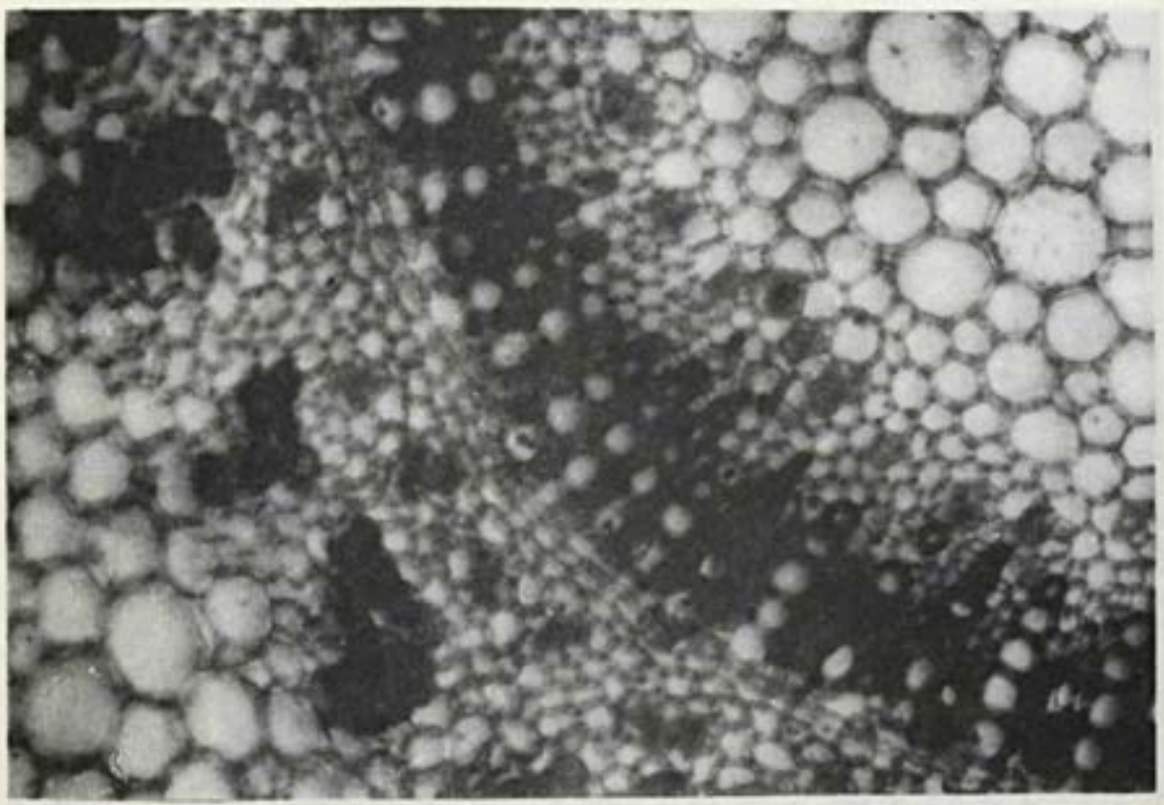

Fig. 12 - Corte transversal do caule jovem $(100 \mathrm{X})$ 


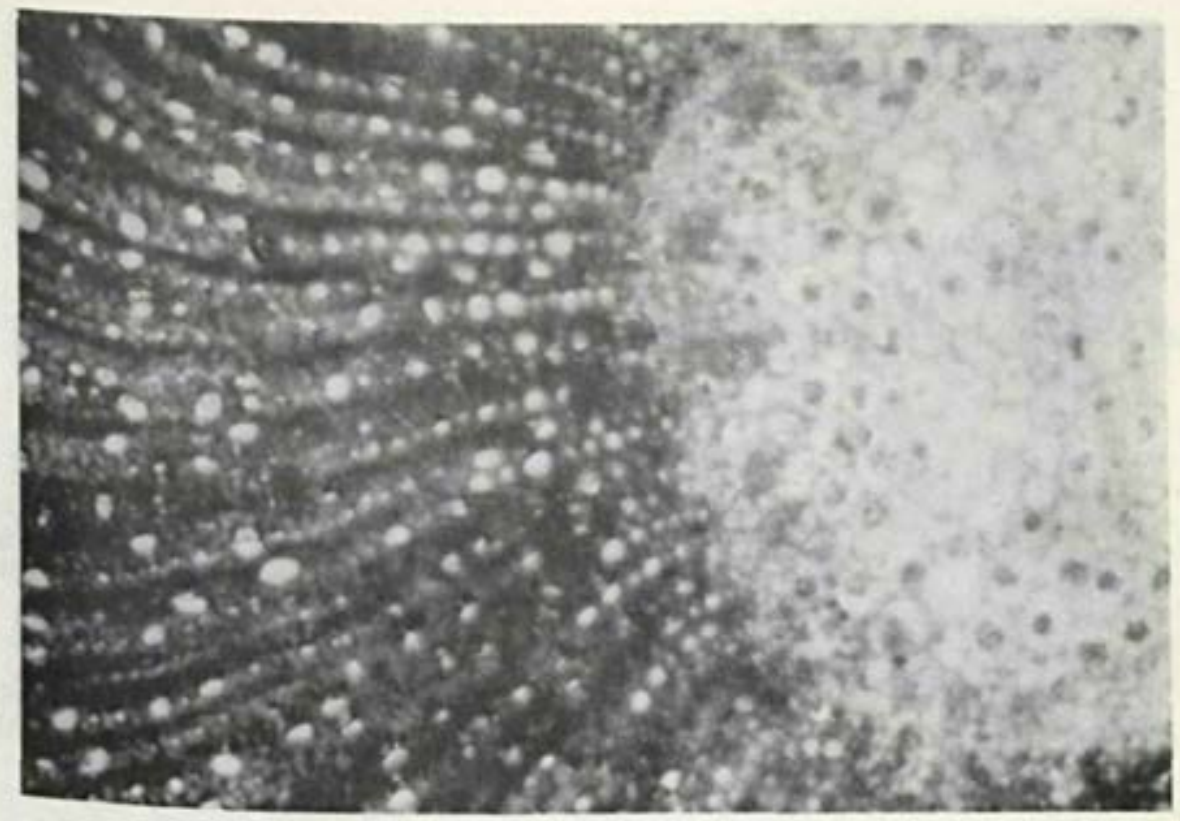

Fig. 13 - Corte transversal do caule de estrutura secundária (63 X)

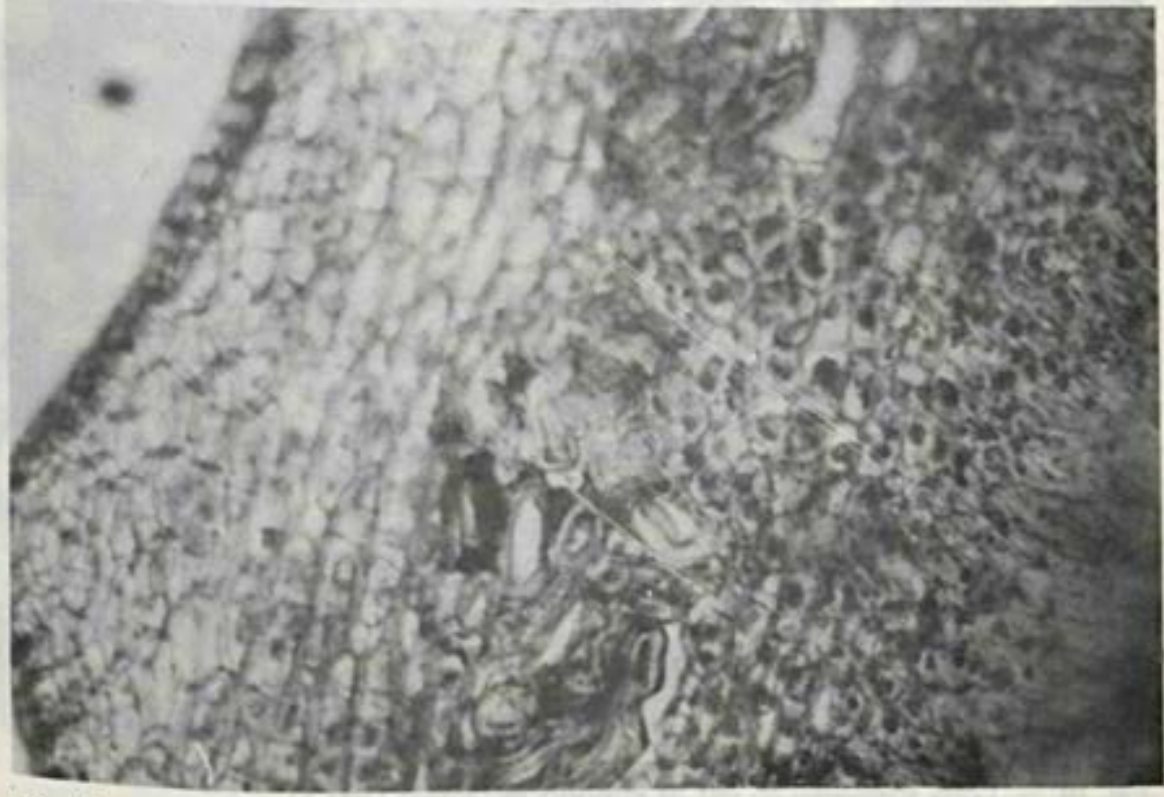

Fig. 14 - Corte transversal do caule de estrutura secundária $(63 \mathrm{x})$ 


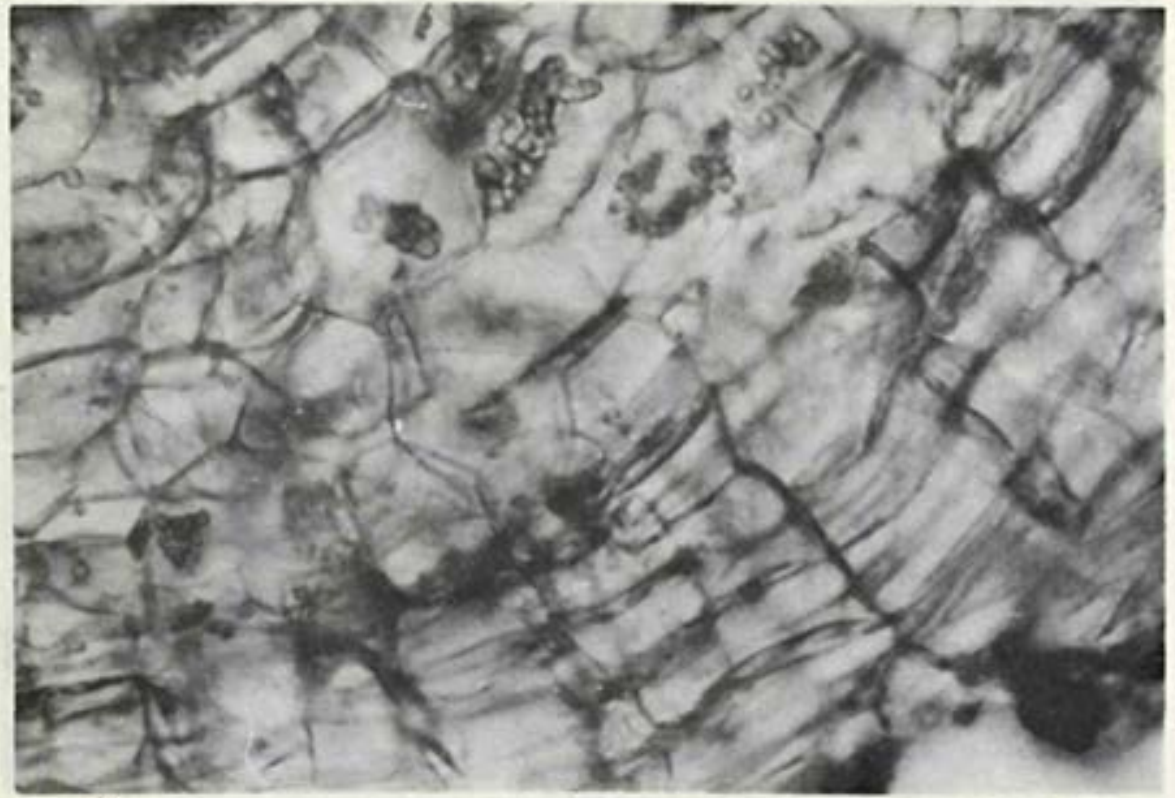

Fig 15 - Corte transversal da raiz de estrutura secundária $(160 \mathrm{X})$

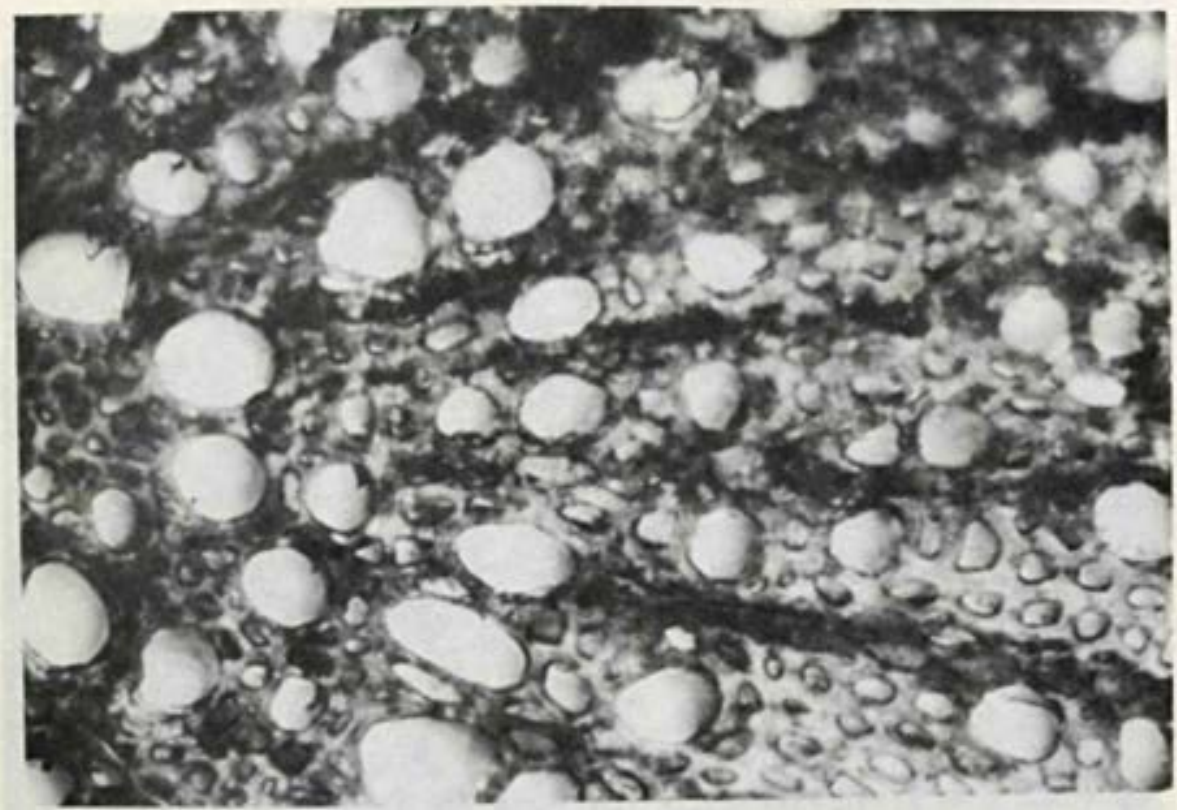

Fig. 16 - Corte transversal da raiz de estrutura secundária (160 X) 